\title{
Early-onset of psychiatric features in mild frontotemporal dementia with impaired memory test: a case report and neuropsychological evaluation
}

\author{
Sintomas psiquiátricos prematuros em demência frontotemporal \\ leve com desempenho deficitário em teste de memória: \\ relato de caso e avaliação neuropsicológica \\ Gabriel Coutinho', Dídia Fortes², Flavia Miele 33 Paulo Mattos ${ }^{4}$
}

\section{DEAR EDITOR,}

Frontotemporal dementia (FTD) is characterized by behavioral changes which may precede cognitive decline, being mainly a presenile disturbance with an insidious onset and high familial incidence'. Degeneration affects mainly prefrontal and temporal anterior brain areas; executive functions (EFs) and language deficits are commonly found. Changes in eating habits and psychosis have being recently studied as earliest symptoms. We present a FTD case starting with mood symptoms, psychosis and compulsions to discuss differential diagnosis.

\section{CASE}

A., male, 61 years-old, right-handed, graduated, recently retired after working as a manager of a company. Relatives reported first mood changes when he was 56, presenting depressive and hippomaniac episodes of brief duration. A change of eating habits followed and the patient lost almost $10 \mathrm{~kg}$ in 3 months. A. believes his neighbors will sue him, despite the lack of reasons. He is spending hours a day organizing documents he believes will be necessary for the legal process; he started presenting fixed idea for cleaning, washing his hands many times a day. A.'s wife reported difficulties to return home after going to the church because he needs to ensure that people will not gather to speak at his back. There is a current though of bankruptcy, despite his high income; he sold his car because of this fear - even after checking his bank balance. He had no history of psychiatric disorders. He was afraid of taking his medicines because of the risk of being "poisoned".

Neuropsychological evaluation: A. presented difficulties to initiate behavior, such as telling the examiner when he finished the task. Performance in memory was below expected for age, both for visual and verbal material. Verbal memory was evaluated through a prose memory test, with weak performance in immediate recall, but a very similar performance in delayed recall - corresponding to normal ranges. The performance in Complex Figure was impaired after a 5 minute delay. Results revealed cognitive inflexibility, planning difficulties, impaired verbal fluency and formulation hypothesis ability and also perseveration. Language was normal. Results are in tables 1 and 2. 
Table 1. Executive functions - cognitive flexibility

\begin{tabular}{lcc}
\hline WCST scores & Raw scores & $\%$ lles \\
\hline Total errors & 35 & $4 \%$ \\
Perseverative responses & 14 & $27 \%$ \\
Perseverative errors & 12 & $30 \%$ \\
Nonperseverative errors & 23 & $1 \%$ \\
Categories completed & 1 & $6 \%-10 \%$ \\
\hline
\end{tabular}

Table 2. Complementary cognitive functions

\begin{tabular}{lccc}
\hline & Raw score & Percentile & Classification \\
\hline Rey Complex Figure - copy & 34 & - & Normal \\
Rey Complex Figure - retrieval & 21 & - & Impaired \\
Vocabulary & 36 & 37 & Normal \\
Matrix & 12 & 50 & Normal \\
Digit Span & 11 & 16 & Low-avarage \\
Blocks & 33 & 50 & Normal \\
Log. Memory immediate recall & 22 & 5 & Borderline \\
Log.Memory late recall & 14 & 25 & Normal \\
Visualspatial span & 15 & 63 & Normal \\
Trail A & 41 (T score) & - & Normal \\
Trail B & 41 (T score) & - & Normal \\
Token Test & 40 & - & Normal \\
\hline
\end{tabular}

\section{DISCUSSION}

Psychiatric features, such as psychosis2 ${ }^{2}$ bipolar disorder ${ }^{3}$ and obsessive-compulsive disorder (OCD) ${ }^{4}$ should be examined because those symptoms might be due to strokes or degenerative processes. In the present case, profile showing prominent EFs deficits, with constructional abilities unimpaired and a peculiar memory impairment, may be important to avoid the misdiagnose of FDT with psychiatric symptoms. Examinee's memory performance might be different from $A D$ individuals mainly because immediate recall of prose memory does not exclusively demand long-term memory structures. This task overloads episodic buffer and central executive (working memory), and the influence of retention is more important in delayed recall. Baddeley and Wilson ${ }^{5}$ demonstrated that amnesic patients could perform normally in prose memory immediate recall, despite having a zero score in delayed recall. The current performance was the opposite, with weak performance in immediate recall, but good performance in delayed recall, showing no retention deficit. Complex figures demand planning abilities (EFs), which might explain impaired performance. This finding is extremely important to differentiate FTD and AD individuals.

\section{REFERENCES}

1. Neary D, Snowden J, Mann D. Frontotemporal dementia. Lancet Neurol. 2005;4:771-80.

2. Loy CT, Kril JJ, Trollor JN, Kiernan MC, Kwok JB, Vucic S, et. al. The case of a 48 year-old woman with bizarre and complex delusions. Nat Rev Neurol. 2010;6(3):175-9.

3. Prabhakar D, Balon R. Late-onset bipolar disorder: a case for careful appraisal. Psychiatry (Edgemont). 2010;7(1):34-7.

4. Frydman I, Ferreira-Garcia R, Borges M, Velakoulis D, Walterfang M, Fontenelle L. Dementia developing in late-onset and treatment-refractory obsessive-compulsive disorder. Cog Behav Neurol. 2010;23(3):205-8.

5. Baddeley A, Wilson B. Prose recall and amnesia: implications for the structure of working memory. Neuropsychologia. 2002;40:1737-43. 